\title{
Why do men have nipples?
}

\section{John Launer}

Every day the home page of my internet service offers a selection of trivia including news of celebrities who are either sleeping with each other or splitting up. There is also usually an item of popular science, often packaged as 'the latest research'. If one of these catches my eye I sometimes click on the link to read it in more detail. Two items I recently followed up in this way were headed 'Why do women live longer?' and 'Why do men have nipples?'. The answers to these tantalising questions weren't nearly as interesting as I hoped. In fact both were pretty old news. The reason women live longer, it said, is because their cells are better at repairing damage in later life. Men have nipples because embryos are always female in their early stages, and males only differentiate from the female prototype after a few weeks. Unfortunately the problem with these explanations wasn't just their banality. They are merely accounts of how things happen, not actually why. They don't address purpose, and hence don't really answer the questions at all. In the language of biological science, they are proximate explanations but not distal ones.

This confusion of mechanisms with purpose-or of proximate causes with distal ones-doesn't just occur in the media. It's very common in medicine as well. If you ask most doctors for the cause of diabetes they may be able to give you an account of how insulin receptors work; they will look puzzled or offended if you tell them they haven't answered your question-but of course they haven't. All they have done is to trace a common pattern of human malfunction from the level of the whole organism back to the molecular level. That, of course, may be tremendously helpful knowledge and indeed lifesaving, but it leaves out whole realms of understanding. How many endocrinologists, I wonder, could tell you the proportion of mammalian species that are prone to diabetes, or at what stage in evolutionary history insulin resistance first appeared, and whether there are any

Correspondence to Dr John Launer, London Deanery, Stewart House, London WC1B 5DN, UK;

jlauner@londondeanery.ac.uk credible hypotheses regarding the purpose this may originally have served?

\section{EVOLUTIONARY FRAMEWORK}

Writing in the Lancet a couple of years ago, Randolph Nesse argued the case for teaching medical students an evolutionary framework for an understanding of the body and disease. ${ }^{1}$ Nesse suggested we should all be able to answer questions like these: 'Why do we all have wisdom teeth, an appendix, and cells that can divide out of control?'. Instead of explaining why people are different, he proposed, a knowledge of evolution would help us recognise why we are similar in the ways we are vulnerable to disease. He pointed out how doctors often have fundamental misconceptions about some of the most basic principles of evolution. As an example, he cited the common but erroneous belief that natural selection operates for the benefit of whole groups rather than just the individual-a belief that has been thoroughly debunked in evolutionary studies. He also listed some of the many biological mechanisms and pathological conditions for which there are now cogent evolutionary explanations, including jaundice, congestive heart failure, senescence, and antibiotic resistance.

I agree with Nesse that knowledge of fundamental evolutionary principles is often lacking in doctors and medical students. I would add some other common misconceptions to his list. For example, I still regularly hear evolutionary 'explanations' based on the Lamarckian fallacy that lifetime experience can affect the genes of the next generation. I come across accounts of evolutionary processes that confuse natural selection with sexual selection-a basic distinction in Darwinian thinking. Pseudo-explanations are also common. The most popular of these is that low back pain is a consequence of standing upright. This is in fact nonsense. Bipedalism evolved because the apes that came down from the trees to the savannah needed to stand up to scan the horizon for predators and prey. Nomads who continue this style of life, and squat in order to eat or defecate instead of using chairs or pedestal toilets, don't suffer from endemic back pain as we do in the western world.
In the same way, I regularly challenge students of psychiatry, psychology, and other mental health professions who have never been taught there are perfectly good evolutionary accounts of depression, varieties of sexual desire, and a whole range of apparent disorders of mental function. ${ }^{2}$ These accounts offer convincing explanations of why human feelings and behaviour have evolved as adaptations to different kinds of environmental circumstances. Indeed, one of the advantages of evolutionary thinking is that it takes you away from simplistic assumptions of what is normal and abnormal in human emotions, and places everything instead within a framework of sense-making.

\section{BROAD CONSENSUS}

So what are the best explanations for the two questions posed but not actually answered by my internet service? The first one is quite easy to address, and an area of broad consensus among evolutionary scholars. Human females live longer than males largely because the function of grandmothers in child rearing is far more important that that of grandfathers. Once males have outlived their potential for hunting prey, they have historically been of relatively little use for the infants and children of their clan. By contrast, the females have traditionally supported their daughters in rearing the third generation. As a result, natural selection has favoured girls with genes for longevity who can survive to protect their descendants. The proximal, sex-linked cellular mechanism that mediates this survival is evidence of this purpose. The same kinds of selective pressures have also led to women losing their reproductive capacity in mid-life while male fertility continues until death. Babies with very old mothers don't tend to survive because their mothers are likely to die too soon to rear them to a selfsufficient age. Whether or not their fathers remain alive is less important.

Male nipples, however, are more perplexing, and I am not sure I have yet come across a completely plausible distal explanation. We know that mammalian nipples and lactation evolved originally from sweat glands. It seems clear that over a period of millions of years, infants who could cling to their parents and suckle on increasingly nutritious secretions from this source must have had an adaptive advantage. They obviously did better than others who were fed on thinner, more dilute fluid, or who had a less protuberant teat to feed from. Perhaps in 
early mammals, males as well as females may have developed the same capacity for secreting nutritious sweat, only for this to become redundant as a result of later evolutionary pressures.

An alternative and perhaps more convincing explanation is that the original adaptation served a dual purpose of physical attachment as well as lactation, so that it was of benefit to infants for both their parents to have this accessory on their chests.

Similarly, we know that nipples have an erogenous function in females; both sexual stimulation and lactation promote a sense of arousal and of close emotional connection, each mediated by a surge of endorphins. Nipples are also erogenous in around $50 \%$ of men, who have the same physiological and emotional response. This suggests that they may have evolved in order to serve a significant function in courtship and mating behaviour, and in promoting paternal engagement in child-rearing.

Each of these hypotheses certainly fits with what we know of how evolution works, and it's possible that more than one of them is correct. If any readers know of alternative ones that make evolutionary sense, I'd also be happy to learn about them. Almost certainly, I shall find them more interesting than any of the celebrity scandals or other trivia that my internet home page has on offer.

Competing interests None.

Provenance and peer review Commissioned; not externally peer reviewed.

Postgrad Med J 2011;87:79-80.

doi:10.1136/pgmi.2010.113977

\section{REFERENCES}

1. Nesse RM. Evolution: medicine's most basic science. Lancet 2008:372:S21-7.

2. Stevens A, Price J. Evolutionary Psychiatry: A New Beginning. 2nd edn. London: Routledge, 2000. 